\title{
The Use of Reconstruction Plates and Add-on Condyles with an Alloplastic Unmatched Fossa, Following Partial Mandibulectomy with Disarticulation
}

\author{
Jameel Desai ${ }^{1}$, Coelette Smit $^{2}$ \\ ${ }^{1}$ Department of Maxillofacial and Oral Surgery, University of Pretoria, Tshwane, South Africa \\ ${ }^{2}$ Advanced Orofacial Surgery, Rosebank, South Africa
}

Email address:

drdesai@maxfac.co.za (J. Desai), coelette.smit@gmail.com (C. Smit)

To cite this article:

Jameel Desai, Coelette Smit. The Use of Reconstruction Plates and Add-on Condyles with an Alloplastic Unmatched Fossa, Following Partial Mandibulectomy with Disarticulation. Journal of Surgery. Vol. 7, No. 2, 2019, pp. 31-34. doi: 10.11648/j.js.20190702.11

Received: January 22, 2019; Accepted: April 9, 2019; Published: May 6, 2019

\begin{abstract}
The reconstruction of a mandible after ablative surgery poses many challenges. This is particularly true if the temporomandibular joint (TMJ) has been sacrificed, and the intention is to replace the mandibular defect and the joint with an alloplastic reconstruction plate and add-on condyle. A metal only condyle poses serious complication risk, and thus function against a prosthetic fossa is desirable. Currently, no stock matched prosthesis exists to fulfil this role. Aim: a series of cases are presented, whereby unmatched add-on condyles and alloplastic fossas were used safely and effectively. Materials and method: nine patients that received hemi-mandibulectomies and subsequent reconstruction with reconstruction plates, add-on condyles and alloplastic TMJ fossas, were retrospectively reviewed. The radiographs were reviewed for structural integrity of the prostheses, or the formation of heterotypic bone; and the patients were clinically evaluated for localised signs of sepsis or dehiscence. Results: all nine patients showed no sign of clinical or radiographic failure of the hybrid prostheses. Conclusion: it appears as though the use of unmatched TMJ fossas and reconstruction plates with add-on condyles, are an acceptable method of treating an ablated TMJ after hemi-mandibulectomy with disarticulation.
\end{abstract}

Keywords: Mandibular-Reconstruction, Add-on Condyle, Alloplastic Fossa, Temporomandibular Joint

\section{Introduction}

The reconstruction of a hemi-mandibulectomy or partial mandibulectomy with disarticulation presents a significant reconstructive challenge and remains a contentious topic. Some surgeons tend to favour the reconstruction with an autogenous costochondral graft [1-3], whilst others favour an alloplastic mode of repair [4-5]. What has become fairly evident, is that a hemi-arthroplasty replacing the articular fossa might be acceptable; but there are long term complications surrounding just condylar replacement [6-7]. Currently there exists three FDA approved (in America) matched condylar / fossa prostheses for the explicit use of total joint replacement (TJR). The companies together with their key researchers are: Biomet/Lorenz Microfixation (Jacsonville, Florida, USA) with PD Quinn, FDA 1995 [8]; TMJ Concepts/Techmedica (Ventura, California, USA) with LM Wolford and LG Mercuri, FDA 1999 [9-10] and Nexus
CMF/TMJ Medical/TMJ Implants (Golden, Colorado, USA) with RW Christensen, FDA 2001 [11-12]. When ablative TMJ disarticulation has been done, and a reconstruction plate with add-on-condyle has been used; there are no specific matched fossa component. Some surgeons have circumvented this by using a metal condyle with interpositional fat, cartilage, articular disc or muscle grafts. These methods however also result in complications such as dehiscence, dystrophic bone formation and perforation of the external auditory canal [6-7]. The use of a condyle against a bare Glenoid fossa, is to be discouraged as the erosion of the Glenoid fossa, with intracranial migration of the condyle becomes a real possibility [7]. In South Africa, as it probably would be in most developing countries, patients present at a late stage with both benign and malignant jaw tumours [Figure 1]. This unfortunately leads to a large number of 
partial mandibulectomies with mandatory disarticulation. A series of cases, whereby unmatched add-on condyles and alloplastic fossas that were used safely and effectively as part of a definitive reconstruction is presented.

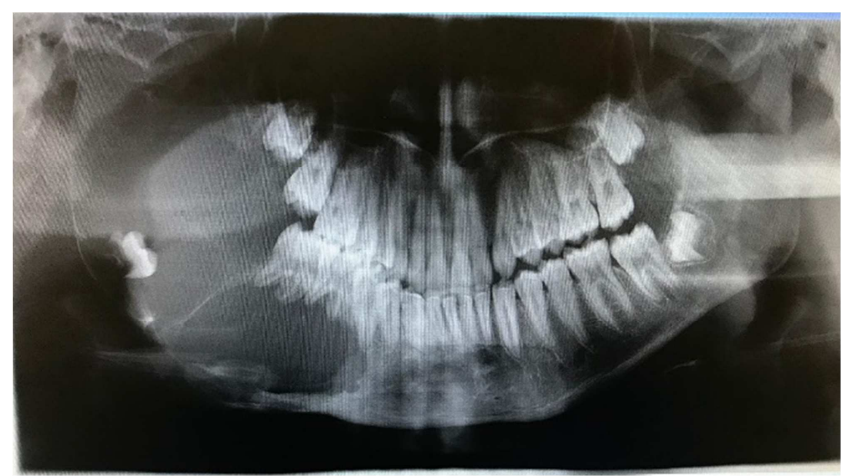

Figure 1. Orthopantomograph shows extensive tumour (Ameloblastoma) in the right hemi-mandible with extension into the right condyle.

\section{Material and Method}

A series of nine patients requiring partial mandibulectomy with disarticulation of the TMJ, were treated with interim reconstruction (2008-2017). The indication for the mandibulectomies were all due to extensive non-malignant but neoplastic mandibular bone tumours, with extension into the condylar heads. Patients with malignant tumours and those that had reconstructions followed by radiation therapy, were not included in the sample. The tumours were resected predominantly via a combined trans-oral and preauricular approach, with 2 patients requiring extra oral tumour resection. The reconstruction made use of Synthes preformed (DePuy Synthes CMF, West Chester, PA) and Biomet (Zimmer Biomet CMF, Jacksonville, FL, USA) reconstruction plates and their respective add-on condylar head systems. The glenoid fossa prosthesis used in all cases was the ultra-high molecular weight polyethylene (UHMWPE) component, provided by Biomet (Zimmer Biomet CMF, Jacksonville, FL, USA) [11]. This fossa prosthesis is the one used in the Biomet Zimmer total joint replacement system, and is unmatched to neither the Synthes nor the Biomet reconstruction plate add-on condyles. The patients were followed up clinically and radiographically (panoramic radiographs) at 2, 612 , and 24 weeks postsurgery; and three patients were seen greater than 12 months after surgery. Patients were assessed clinically for signs of failed or failing prostheses, which included unsolicited preauricular pain, trismus, skin dehiscence and signs of localised sepsis over the TMJ area. Radiographically, we assessed for dystrophic bone formation in the TMJ area and structural integrity of the prostheses (fracture of the plate or screw loosening). Both authors assessed all 9 patients clinically and radiographically, and consensus was achieved regarding the interpretation of the assessments. Consent to perform the surgeries, and permission to use the radiographs and clinical pictures were obtained.

\section{Results}

The sample of 9 patients included 3 females and 6 males aged between 17 and 63 yrs (mean age 27 years). The hemimandibulectomies were performed secondary to benign neoplasms (8 Ameloblastomas and 1 Ameloblastic Fibroma). The resections wherever possible were performed intraorally (7 of 9), and a pre-auricular approach for the placement of the fossa prosthesis was always used ( 9 of 9) figures 2 and 3. Of all the resections done, 6 were done to the right and 3 to the left hemi-mandibles. Clinically there were $0 / 9$ cases of sepsis, trismus or pain reported at 12 weeks or greater; whilst the radiographs were also all negative for failure. Failure would be considered were there found to be any screw loosening either on reconstruction plates or the UHMWPE fossa prostheses. Any fracture of the reconstruction plates would also be considered as a failure.

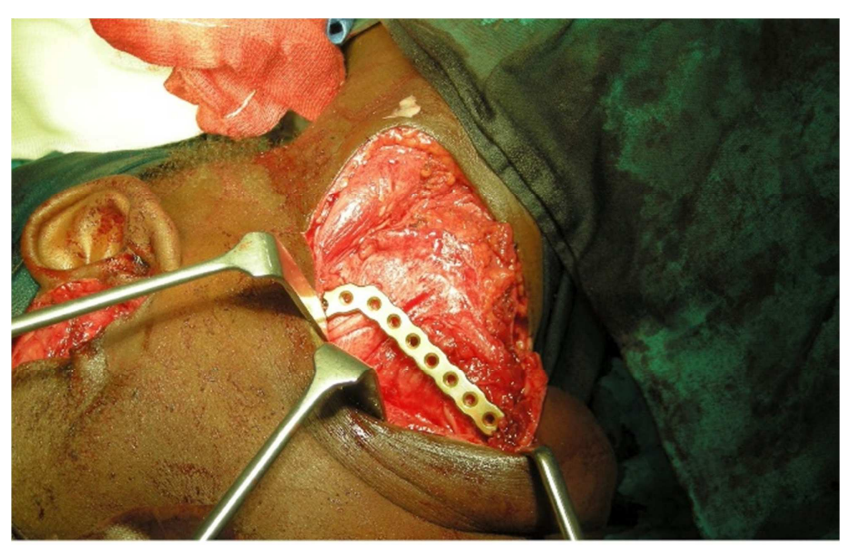

Figure 2. Clinical photograph shows the partial hemi-mandibulectomy with Biomet reconstruction plate fitted in the defect (2008).

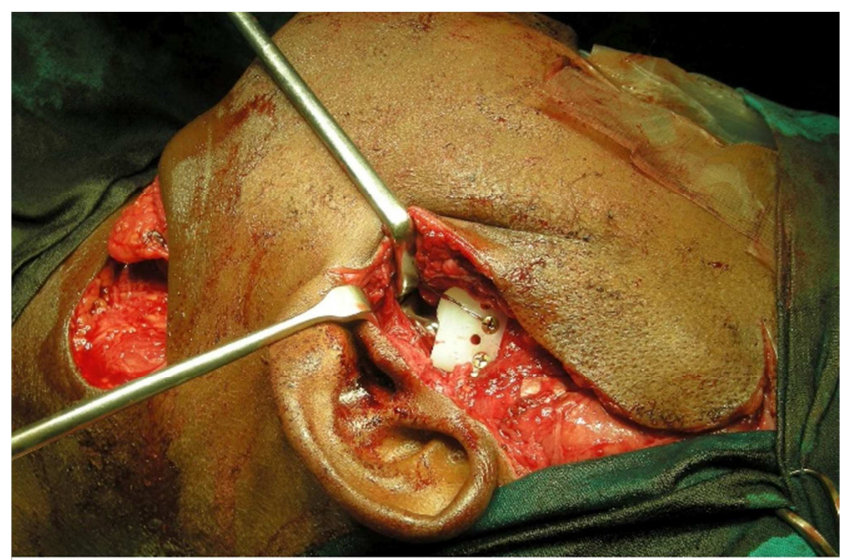

Figure 3. Clinical photograph shows the add-on condyle fitted to reconstruction plate and the unmatched Biomet stock TMJ fossa prosthesis (2008). 
Table 1. Data table representative of the cases done over a 10 year period 2008-2018.

\begin{tabular}{|c|c|c|c|c|c|c|}
\hline Patient & Treatment date & Gender & Age & Pathology & Site & Prosthesis \\
\hline SP & $13 / 11 / 2008$ & $\mathrm{~F}$ & 26 & Ameloblastoma & $\begin{array}{l}\text { L CONDYLE TO } \\
\text { SYMPHYSIS }\end{array}$ & $\begin{array}{l}\text { W. LORENZ PLATE ADD ON } \\
\text { CONDYLE FOSSA }\end{array}$ \\
\hline NP & $12 / 07 / 2017$ & M & 27 & Ameloblastoma & R CONDYLE TO SYMPHYSIS & $\begin{array}{l}\text { SYNTHES PREFORMED } \\
\text { CONDYLE FOSSA }\end{array}$ \\
\hline NL & $23 / 11 / 2017$ & M & 18 & Ameloblastoma & $\begin{array}{l}\text { R CONDYLE TO R } \\
\text { P/SYMPHYSIS }\end{array}$ & $\begin{array}{l}\text { BIOMET RECON CONDYLE } \\
\text { FOSSA }\end{array}$ \\
\hline MDM & $23 / 11 / 2017$ & M & 17 & Ameloblastoma & $\begin{array}{l}\text { R CONDYLE TO R } \\
\text { P/SYMPHYSIS }\end{array}$ & $\begin{array}{l}\text { SYNTHES PREFORMED } \\
\text { CONDYLE FOSSA }\end{array}$ \\
\hline TMB & $25 / 01 / 2012$ & $\mathrm{~F}$ & 24 & Ameloblastoma & R CONDYLE TO R BODY & $\begin{array}{l}\text { W.LORENZ PLATE ADD ON } \\
\text { CONDYLE FOSSA }\end{array}$ \\
\hline MSR & $25 / 01 / 2018$ & M & 63 & Ameloblastic fibroma & L CONDYLE TO L BODY & $\begin{array}{l}\text { SYNTHES PREFORMED } \\
\text { CONDYLE FOSSA }\end{array}$ \\
\hline KRM & $17 / 10 / 2017$ & $\mathrm{~F}$ & 37 & Ameloblastoma & L CONDYLE TO L ANGLE & $\begin{array}{l}\text { SYNTHES PREFORMED } \\
\text { CONDYLE FOSSA }\end{array}$ \\
\hline KG & $17 / 10 / 2017$ & M & 18 & Ameloblastoma & R CONDYLE TO R BODY & $\begin{array}{l}\text { SYNTHES PREFORMED } \\
\text { CONDYLE FOSSA }\end{array}$ \\
\hline MJP & $19 / 03 / 2018$ & M & 19 & Ameloblastoma & $\begin{array}{l}\text { L CONDYLE TO R } \\
\text { P/SYMPHYSIS }\end{array}$ & $\begin{array}{l}\text { SYNTHES PREFORMED } \\
\text { CONDYLE FOSSA }\end{array}$ \\
\hline
\end{tabular}

\section{Discussion}

The alloplastic TMJ prosthesis is exposed to increased compression forces when compared to a contralateral normal TMJ [13]. It stands to reason that a metal condyle without an intervening prosthetic fossa would be destructive were it exposed to the same degree of compressive forces. Several surgeries making use of this technique have been performed [figures 4/5], and have not had any complications pertaining to the "hybrid" TMJ prosthesis; whatsoever. Patient function in terms of mouth opening and ability to chew, was most acceptable; the only noticeable change being jaw deviation to the ipsilateral side upon mouth opening, but this seemed to visually improve 6 weeks after surgery. It has to be reiterated that this technique whilst being in use since 2008, remains an "off label" use. An obvious way around this reconstruction conundrum, would be to use a patient specific custom 3D implant [14], but this comes at considerably higher financial cost; a luxury not routinely available to patients in the South African public health care system. There exists currently no condylar add-on system with its own dedicated fossa prosthesis, as no FDA approval has been obtained for such. The suggestion is for these prostheses (add-on condyles and reconstruction plates) to be used only as an interim solution (maximum of 1 year), whist patients await definitive reconstructions such as free vascularised grafts (eg. fibula graft). In an attempt to decrease the burden of case load and get as many patients as possible, disease free; South African surgeons perform a large number of ablative surgeries and as a result require some form of interim reconstruction. Patients would at times be lost to follow up, and would exceed the recommended 1-year period of using an interim reconstruction modality. Often patients would be happy to have their facial form returned to near normal and refuse any definitive reconstruction; hence the reason for pairing unmatched fossas and add-on condyles. This is to improve function and to minimise the risk of complication; most notably the dangerous phenomenon of condylar head migration or displacement into the middle cranial fossa. In the South African setting, the use of the "hybrid prosthesis" remains a viable way of providing a functional scaffold, for the subsequent bony reconstruction of the mandible, after ablative surgery. The "hybrid" prosthesis fulfils the criteria for success, as outlined by Mercuri's review article [15]. Surgeons faced with similar challenges, could make use of this technique, provided that patients are informed, and consent for its "off label" use.

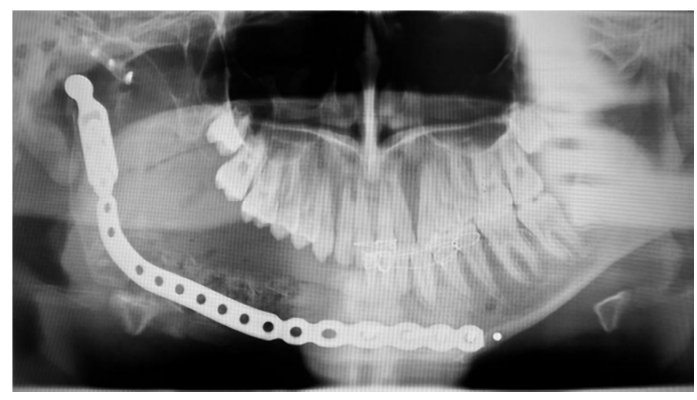

Figure 4. Orthopantomograph showing reconstructed right hemimandibular defect with reconstruction plate (Synthes), add-on condyle and Biomet fossa in a $17 \mathrm{yr}$. old male patient.

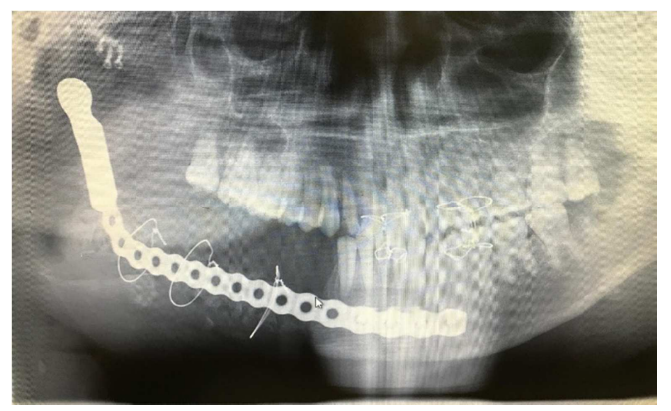

Figure 5. Orthopantomograph showing reconstructed right hemimandibular defect with reconstruction plate (Biomet Zimmer), add-on condyle and Biomet fossa in a $33 \mathrm{yr}$, old male patient.

\section{Conclusion}

Add-on-condyles with an unmatched alloplastic fossa 
("hybrid TMJ prosthesis") have been successfully used since 2008 [Figures 2/3]. This technique provides a viable alternative to using autogenous interpositional graft material, or worse no interpositional material between add-on-condyle and glenoid fossa. In this case series, there were no failure of prostheses due to plate fracture, or for any other reason.

\section{Conflict of Interest}

The authors declare that they have no competing interests.

\section{Funding}

No funding obtained.

\section{Ethics Approval}

Ethical clearance was not required in this instance.

\section{References}

[1] Mercuri LG. Condyle replacement after tumor resection: comparison of individual prefabricated titanium implants and costochondral grafts. Oral surg Oral Med Oral Pathol Oral Radiol and Endodontol 2009;108(2):153-155

[2] Westermark A, Koppel D, Leiggener C. Condylar replacement alone is not sufficient for prosthetic reconstruction of the temporomandibular joint. Int $\mathrm{J}$ Oral Maxillofac Surg 2006;35(6):488-492

[3] Van Loon J-P, Otten E, Falkenström CH, de Bont LGM, Verkerke GJ. Loading of a unilateral temporomandibular joint prosthesis: a three dimensional mathematical study. J Dent Res 1998;77(11):1939-1947

[4] Westermark A, Hedén P, Aagaard E, Cornelius C-P. The use of TMJ concepts prostheses to reconstruct patients with major temporomandibular joint and mandibular defects. Int J Oral Maxillofac Surg 2011;40:487-496
[5] Mercuri LG. Alloplastic temporomandibular joint reconstruction. Oral Surg Oral Med Oral Pathol 1998;85(6):631-637

[6] Lindqvist C, Söderholm AL, Hallikainen D, Sjövall L. Erosion and heterotopic bone formation after alloplastic temporomandibular joint reconstruction. J Oral Maxillofac Surg 1992;50:942-949

[7] Gilles HD. Plastic surgery of the face. London: Oxford; 1920

[8] Kaban LB, Bouchard C, Troulis MJ. A protocol for management of temporomandibular joint ankylosis in children. J Oral Maxillofac Surg 2009;67:1966-1978

[9] Perrot DH, Umeda H, Kaban LB. Costochondral graft construction/reconstruction of the ramus condyle unit: long term follow up. Int J Oral Maxillofac Surg 1994;23:321-328

[10] Mario JI, Aaron L. Temporomandibular joint reconstuction. Curr Opin Otolaryngol Head Neck Surg 2016;24:336-342

[11] Quin PD. Total TMJ reconstruction with alloplasts: an overview. J Oral Maxillofac Surg 1995;53 (Suppl):55-65

[12] Wolford LM, Cottrell DA, Henry CH. Temporomandibular joint reconstruction thesis. J Oral and Maxillofac Surg 1994;52:2-10

[13] Mercuri LG, Wolford LM, Sanders B et al. Custom $\mathrm{CAD} / \mathrm{CAM}$ total temporomandibular joint reconstruction system: preliminary multicenter report. J Oral Maxillofac Surg 1995;53:106-115

[14] Chase DC, Hudson JW, Gerhard DA, et al. The Christensen prosthesis. A retrospective clinical study. Oral Surg Oral Med Oral Pathol Oral Radiol Endod 1995;80:273-278

[15] Garrett WR, Abbey PA, Christensen RW. Temporomandibular joint reconstruction with a custom temporomandibular joint prosthesis: use in the multiply operated patient. In Szabo Z, Leis JE, Fantini GA, editors. Surgical technology international. San Francisco, CA: Universal Medical 1997. pp. 347-354 